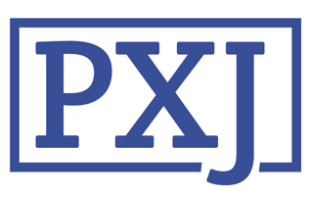

Patient Experience Journal

Volume 3 | Issue 1

Article 6

2016

\title{
Can social media reduce discrimination and ignorance towards patients with long term conditions? A chronic kidney disease example in the UK and more widely
}

Shahid N. Muhammad

The Renal Patient Support Group (RPSG)

Amy J. Zahra

2National Commission Persons with Disabilities (NCPD), Malta

Howard J. Leicester

3 Health Informatics and Data Accessibility, One Voice Coalition for Accessible Information

Communication Technology (ICT), England UK

Heather Davis

4The Kidney Disease and Renal Support (KDARS) Group for Young People with Chronic Kidney Disease (CKD), England UK

Stephen Davis

The Kidney Disease and Renal Support (KDARS) Group for Young People with Chronic Kidney Disease (CKD), England UK

Follow this and additional works at: https://pxjournal.org/journal

Part of the Disability and Equity in Education Commons, Family, Life Course, and Society Commons, Health Information Technology Commons, Inequality and Stratification Commons, Leadership Studies

Commons, Politics and Social Change Commons, and the Service Learning Commons

\section{Recommended Citation}

Muhammad SN, Zahra AJ, Leicester HJ, Davis H, Davis S. Can social media reduce discrimination and ignorance towards patients with long term conditions? A chronic kidney disease example in the UK and more widely. Patient Experience Journal. 2016; 3(1):35-41. doi: 10.35680/2372-0247.1049.

This Article is brought to you for free and open access by Patient Experience Journal. It has been accepted for inclusion in Patient Experience Journal by an authorized editor of Patient Experience Journal. 


\section{Can social media reduce discrimination and ignorance towards patients with long term conditions? A chronic kidney disease example in the UK and more widely}

\section{Cover Page Footnote}

The Authors and Co-Authors would like to kindly acknowledge members of The Renal Patient Support Group (RPSG), and The Kidney Disease and Renal Support (KDARS) Group for Young People with Chronic Kidney Disease (CKD) 


\title{
Can social media reduce discrimination and ignorance towards patients with long term conditions? A chronic kidney disease example in the UK and more widely \\ Shahid Muhammad, The Renal Patient Support Group (RPSG), The Royal Devon and Exeter NHS Foundation Trust, smuhammad1@nbs.net
}

Amy Camilleri-Zahra, University of Malta, amy.camilleri-zabra@um.edu.mt

Howard James Leicester, Health Informatics and Data Accessibility, One Voice Coalition for Accessible Information

CommunicationTechnology,England UK, howard_leicester@btconnect.com;

Heather Davis, The Kidney Disease and Renal Support (KDARs) Group for Young People with Chronic Kidney Disease, sjdavis13@hotmail.co.uk

Stephen Davis, The Kidney Disease and Renal Support (KDARs) Group for Young People with Chronic Kidney Disease, sjdavis13@hotmail.co.uk

\begin{abstract}
Long Term Conditions (LTCs) are increasing in prevalence and cost in Western healthcare. Patients with such conditions are often classed as "disabled", because of impacts of self-care on "activities of daily life" or secondary consequences of conditions (impairments) affecting factors such as mobility, concentration and communications. Disability needs are often ignored in the design of services and treatment of individuals. It manifests as services which some find difficult to use and lack of personal respect (discrimination) often based on lack of understanding by the healthcare profession itself (ignorance). This paper explores how Social Media (SM), an example "Assistive Technology" in an increasingly digital age, might help. The focus is Chronic Kidney Disease with two, specific illustrations in the UK beginning to spread worldwide. Support mechanisms now emerging may go well beyond healthcare, and even beyond kidney problems. They may also find additional assistance via the new, English Accessible Information Standard.
\end{abstract}

\section{Keywords}

Discrimination, ignorance, disability, long-term conditions, social media, awareness, assistive technology, communication

\section{Introduction}

The UK's Renal Patient Support Group (RPSG) has revealed many features of unacceptable service and support towards kidney patients in multiple areas. These have been previously reported in a special poster presentation for the Patient Engagement Network (PEN) ${ }^{1}$, which outlined two key themes through some fundamental discussions via the RPSG: 1) Lack of Awareness, Education and Understanding and 2) Disease Sensitivity and Patient Experience. These themes highlighted examples of what is technically against national and international law, known formally as "discrimination" and often based on more fundamental "ignorance". Renal groups have begun to find potential ways round such personal and health system challenges through Social Media. This is an illustration of the wider concept of "Assistive Technologies" starting to help individuals and families at a very direct level, and increasingly among patients around the world. The Patient and Public Involvement (PPI) approach, at NHS England, are beginning to take note. Reinforcement may well come from a requirement to make communications easier in healthcare, including communication channels and platforms like Social Media, known as the Accessible Information Standard (or AIS).

\section{Objective}

This article uses Chronic Kidney Disease (CKD) as an example to other Long-Term Conditions (LTCs). It explains terms, puts experiences and consequences in context of Discrimination and Ignorance. Above all, this article aims to show what is already being achieved and which, with healthcare system support, could well be a model for future developments. 


\section{The Wider Context of Long Term Conditions (LTCs)}

\section{LTCs and Disability}

An estimated 15 million people in England alone have at least one Long Term Condition (LTC). These patients account for around $50 \%$ of GP appointments, $64 \%$ of outpatient appointments and $70 \%$ of hospital bed days ${ }^{2}$. Around $70 \%$ of total health and care expenditure in England is attributed to people with LTCs. ${ }^{2}$ People diagnosed with a number of LTCs are the most intensive users of health and social care services because their needs are usually more complex than those of people with single diseases. Most people aged 65 and over have multimorbidity although a recent Scottish study found the absolute number of people with multi-morbidity was higher in those aged under 65, indicating its implications for the population as a whole. ${ }^{3}$ The number of people with multiple LTCs (known as multi-morbidity) is set to rise from 1.9 million in 2008 to 2.9 million in $2018 .^{2}$ This consequently has an impact beyond health itself. ${ }^{3}$

LTCs also prove to be within another special class. According to Article 1 of the United Nations Convention on the Rights of Persons with Disabilities (UNCPD), person/s with disabilities include:

"Those who have long-term physical, mental, intellectual or sensory impairments which in interaction with various barriers may hinder their full and effective participation in society on an equal basis with others". 3

The World Health Organization (WHO) Global Disability Action Plan now becomes especially relevant: ${ }^{3,4}$

"Across the world, more often than their non-disabled peers, people with disabilities do not receive the health care they need and have poorer health. People with disabilities are more than twice as likely to find healthcare providers' skills and facilities inadequate; nearly three times more likely to be denied health care; and four times more likely to be treated badly".

Specifically in The West, persons with disabilities tend to report more access to health care problems than persons without disabilities. These problems tend to be most common among those with the poorest health and those with the most severe disabilities. ${ }^{3-14}$ According to Drainoni et al. ${ }^{3}$ it is imperative that healthcare policymakers, planners and providers understand and address the needs of people with disabilities as a distinct category of healthcare consumers. ${ }^{14}$ Putting all this in context for this paper, the prevalence of Chronic Kidney Disease (CKD), cancers and diabetes is rising most quickly. ${ }^{2}$ Coping strategies also have a large role to play living with a LTC, especially for young people with CKD. ${ }^{4,15}$

\section{Discrimination and Ignorance}

From the UN Convention on Rights of Persons with Disability (UNCPD), discrimination is defined as:

"Any distinction, exclusion or restriction on the basis of disability which has the purpose or effect of impairing or nullifying the recognition, enjoyment or exercise, on an equal basis with others, of all buman rights and fundamental freedoms." 4

Discrimination in the UK is more explicitly defined as distinguishing differences between treating someone as inferior based on their race, sex, health background, national origin, age or other characteristics. ${ }^{5}$ There have been signs of a developing focus upon discrimination. ${ }^{16-18}$ This may be seen as the consequence of stigma, which acts on the disadvantage of people who feel denounced. ${ }^{17-19}$ The importance of discrimination has been transparent for years in terms of the personal experiences of service users, having devastating effects on personal relationships, parenting and childcare, education, training, work and housing. ${ }^{6}$ There is evidence, too, directly from the health profession.

According to a poll commissioned by the General Medical Council (GMC), more than half of the doctors who took part in this poll think that patients with a disability receive a poorer standard of healthcare. More than one in three doctors reported that they had actually witnessed a patient with a disability receiving poorer care or facing some form of discrimination. ${ }^{7}$ This confirms Mencap's claim that that NHS is still putting lives at risk by failing to adhere to the UK Equality Act. ${ }^{13}$

Relating to Discrimination is Ignorance, which is a state of being uninformed (having a lack of knowledge). The word ignorant is an adjective describing an individual or people in the state of being unaware. It is often used as an insult to describe individuals who deliberately ignore or disregard important facts. Ignorance can thus be defined as having a lack of awareness, education or knowledge relating to people with a disability or a LTC. ${ }^{8}$ A more honest admission of ignorance might mean an increase in awareness and understanding of real issues and concerns that patients have in the context of health and social services. ${ }^{17}$ From this evidence, there needs to be an improved access to knowledge widely, especially where people with LTCs or disabilities have challenges. In sum, this means sharpening focus upon human rights, upon discrimination and ignorance as actually experienced by people with a disability or LTC, respectively.

\section{Assistive Technologies illustrated by Social Media} One way of improving the awareness of discrimination and ignorance for a disability or LTC for employers, service users/providers, policy makers and health professionals is pointing them to information and resources where they can gain real experiences and 
understanding. More awareness to preclude discrimination and ignorance can perhaps be achieved through Information and Communications Technology (ICT) Social Media (SM) and Assistive Technology (AT). ${ }^{18-27}$

The working definition for "Assistive Technology" 28 in health and social care, spanning nearly everything, is:

\section{"Any product or service designed to enable independence for disabled and older people".}

The definition was refined for the digital world by Stephen Hawking, in his acceptance speech at Ability net's: "The Tech4Good Awards ${ }^{28}$ remind us that technology is a vital part of human existence. They show us that the right tools in the right hands can help everyone, regardless of our frailties, to achieve our true potential and advance as a civilization".

Social Media (SM) fall within both the Kings Fund and Hawking definitions. Usage has grown exponentially with sites such as Facebook, Twitter, Instagram and others now representing $20 \%$ of time online and much more. ${ }^{29-30}$ Not surprisingly people with disabilities and LTCs seek peerto-peer support via SM which offers advantages over standard forms of engagement/education with wide accessibility, immediacy and offers an opportunity for patient education. ${ }^{31,32}$ The overwhelming penetration of $\mathrm{SM}$ into lives necessitates a renewed commitment to changing the way society addresses the use of media to raise awareness in topics of disability and LTCs and to preclude feelings of discrimination and ignorance. ${ }^{33-35}$

The use of Information Communication and Technology (ICT) and highlighting the challenges of living with a disability or LTC through SM is important for most patients. Many want to be more involved to prompt issues like ignorance and discrimination, which can be overwhelming. ${ }^{8}$ There is also compelling evidence that patients who are active in managing their lives have better outcomes than those who are passive service recipients. ${ }^{36}$ The use of user-friendly ICT and SM services is also important for knowledge and resource acquisition and for integrated care. User-friendly ICT services allow the delivery of better understanding, enhancing care quality efficiencies across care providers, to enable better patient outcomes. $^{37}$

\section{The Chronic Kidney Disease Example}

CKD is an LTC that essentially has been described as the gradual, and usually permanent, loss of kidney function over time. Table 1 summaries the typical deterioration path, based on the kidneys' ability to filter blood (glomerular filtration rate or GFR). ${ }^{38}$

Early in the disease process, people with CKD often experience no symptoms. CKD has, for a long time, been an under-diagnosed disease. ${ }^{38}$ Even in the absence of symptoms, CKD appears to add significantly to the burden of cardiovascular disease (CVD) and death. ${ }^{38}$ Although there is no age limit or race that is 'taken by CKD', the incidence of disease has been changing. In addition, the age of patients entering CKD programmes increased progressively, unfortunately, most of these patients are referred to a nephrologist only at a time when renal function is close to the level where dialysis is required, that is when not much can be expected of conservative kidney protective treatments. ${ }^{38}$

Over the last few years, collaborative efforts, enabled by a common definition of CKD, have provided a description of the epidemiology and natural history of this disease thus improving understanding pathophysiology. There is increased recognition that $\mathrm{CKD}$ is encountered in multiple settings and in all age groups, and that its course and outcomes are influenced by the severity and duration of the event. The effect of CKD on an individual patient and the resulting societal burden that ensues from the long-

\section{Table 1. Stages of CKD (in adult population)}

\begin{tabular}{|c|c|}
\hline CKD Stage & Definition \\
\hline Stage 1 & $\begin{array}{l}\text { Kidney damage with normal or raised GFR } \\
\left(\geq 90 \mathrm{ml} / \mathrm{min} / 1.73 \mathrm{~m}^{2}\right)\end{array}$ \\
\hline Stage 2 & $\begin{array}{l}\text { Kidney damage with normal or raised GFR } \\
\left(60-89 \mathrm{ml} / \mathrm{min} / 1.73 \mathrm{~m}^{2}\right)\end{array}$ \\
\hline Stage 3 & $\begin{array}{l}\text { Moderately impaired GFR } \\
\left(30-59 \mathrm{ml} / \mathrm{min} / 1.73 \mathrm{~m}^{2}\right)\end{array}$ \\
\hline Stage 4 & $\begin{array}{l}\text { Severely impaired GFR } \\
\left(15-29 \mathrm{ml} / \mathrm{min} / 1.73 \mathrm{~m}^{2}\right)\end{array}$ \\
\hline Stage 5 & $\begin{array}{l}\text { End Stage Renal Failure or GFR } \\
\left(<15 \mathrm{ml} / \mathrm{min} / 1.73 \mathrm{~m}^{2}\right)\end{array}$ \\
\hline
\end{tabular}


term effects of the disease is attracting increasing scrutiny. There is evidence of marked variation in the management of CKD due to a lack of awareness and an absence of standards for prevention, early recognition, and intervention. Analysis of patients with unidentified CKD suggests that their risk profile may be different to patients with identified CKD. This is another area that requires further research. ${ }^{39}$ These emerging data point to an urgent need for a global effort to highlight that CKD is preventable, its course is modifiable and its treatment can improve outcomes. ${ }^{40,41}$

\section{The Renal Patient Support Group (RPSG)}

There is emerging research to inform how SM can integrate healthcare. ${ }^{42}$ One example of a well facilitated social group raising CKD awareness is the RPSG, ${ }^{16}$ which is primarily a 'closed' Facebook group, and was initially established in 2009 by two long term renal patients and one long-time carer in Bristol City, UK. The RPSG is largely patient-based and patient/carer led; at present, there are now over 6500 members in the RPSG Facebook group today (and the group continues to grow). There are 10 members who form the administrative/research team with representation from the UK, Europe, Australia and USA who are responsible for moderating the group. The RPSG offers online peer support internationally, with members providing insight on their experiences. ${ }^{43}$

The RPSG is also research active. Since the RPSG is mainly a Facebook platform, this lends itself well to raising CKD allowing members to share real-life stories. ${ }^{17}$ The RPSG is referred to by semi-professional renal sites such as the National Kidney Federation (NKF) and has been endorsed by the Renal Patient View (RPV) team. The RPSG thus allows a platform for all members to share issues and experiences starting with the very patients who suffer with CKD. ${ }^{43}$

Whilst the RPSG may have some initial difficulties collecting data owing to participant motivation/enthusiasm to get involved; using SM also offers opportunity to the general public, patients and health care providers to share experiences and understanding as never done so before. The RPSG slogan is a 'place' where awareness and research meet. ${ }^{43}$ The RPSG has set a precedent for more renal patient support groups to become active via Facebook. The RPSG also has BlogSpot and Research Gate platforms to provide academics/researchers and non-Facebook users an understanding of activities.

\section{The Kidney Disease and Renal Support (KDARS) Group for Young People with CKD}

KDARs is a parallel Facebook support group highlighting $\mathrm{CKD}$ awareness more specifically in young people with
CKD, who can face a lifetime of illness. ${ }^{44,45}$ Following on from the experience that two parents had gone through with respect to one of their children who had been born and diagnosed with Acute Kidney Injury (AKI), for several months they discussed the notion of initiating a support group to provide peer support and better communication pathways for parents/guardians with a child/children who are in CKD.

The parents composed several bulletins and stories approaching their local newspaper, the Grimsby Telegraph making effort to highlight their story. The parents struggled to get any response and had very little success; it was then that the parents contemplated setting up a SM support group for families of youngsters living with CKD. The parents endeavored to 'scan' for other Facebook support groups specific to young people or paediatric patients and also identifying that there were no sizeable groups specific to this population. It was on the 28th April 2014, KDARS was founded. KDARS for Kids is a support group for patients, parents/guardians and carers of babies, toddlers and young people affected by CKD. As parents of a little girl who has suffered with CKD since birth and struggles on a daily basis, the founders know how hard, lonely and isolating living with the CKD "life sentence" can be. Through founding KDARS, the founders hope to encourage families in similar circumstances to share their experiences and stories, to offer support in challenging times and to highlight that parents/guardians are not alone.

KDARS Facebook group aims to fill a 'gap in the market'; to offer support to parents/guardians who have a child in ages of 0-17 years and this is where the support is often neglected and needed most. KDARS have recently reached over 500 members worldwide, with members thus far sharing experiences in Europe, East Asia and USA. Providing support through in this manner has allowed the KDAR founders to provide support through SM where previously non-existent. KDARS is now finally reaching out to parents/guardians who need support.

Whilst utilizing SM has some advantages, the founders want to be on the frontline in order to offer a more face to face service to highlight more crucial topics relating to young people suffering with CKD and parents/guardians who also have their own set of challenges; this includes topics relating to CKD awareness, discrimination and ignorance. The KDARS founders have been offered a free psychotherapist for families and this service has been kindly donated by Hull University. KDARs founders endeavour to identify a suitable physical premise to operate. KDARS founders now also operate a small Tea Shop working to support fellow members in Cleethorpes, England UK because the team encourages members to share experiences and raise concerns outside the SM 
platform, be able to provide literature, communicate face to face and take time out for themselves.

The issues that arise from living with CKD are vast; the KDARS founders want to ensure that awareness for CKD in the young comes to the forefront and want to be able to raise and inform the public's perception of this disease. Many people believe that a transplant is a cure; this is a fallacy. A transplant is a treatment option and this is another message KDARS founders are getting across. There needs to be more awareness and understanding of LTCs like CKD to preclude larger issues on sensitive topics like discrimination and ignorance which have a deeper impact in later life.

\section{Discussion}

Discrimination, potentially based on ignorance, was all too obvious at senior level in 2014. In a recording made during a fringe meeting at the Conservative conference on $25^{\text {th }}$ August. The Minister for Welfare Reform, Lord Freud, responding to a question from a councillor, said:

"You make a really good point about the disabled. Now I had not thought through, and we have not got a system for, you know, kind of going below the minimum wage." "There is a group, and I know exactly who you mean, where actually as you say they're not worth the full wage." 46

Lord Freud's views may not be limited to senior politicians. Evidence also implicates academics, health researchers and employers. ${ }^{47}$ Interestingly, in the September (2015) online edition of the Health Service Journal (HSJ), authors state the following:

\section{"The NHS workforce will increasingly need to attract and retain} staff with disabilities" 48

Assistive Technology (AT) for example should be acknowledged and understood by employers of individuals with disabilities, allowing healthier work environments. More awareness is needed. ${ }^{49,50}$ Benefits from health support often go well beyond the health system itself. Based on implications from Sayce above, other studies have shown employment is needed to not only provide a living but to sustain mental health and wellbeing. ${ }^{20-21}$ Work fulfills a number of basic needs for an individual such as collective purpose, social contact, status, and activity. ${ }^{20} \mathrm{~A}$ person with a disability or LTC can often be socially isolated and work is one way to reduce isolation. ${ }^{51-55}$

The KDARS group is already going beyond SM. In the literature, Peer counselling is another way of fighting discrimination and ignorance. Specifically, this involves the linking of recent persons with disability and LTCs to individuals who have had a disability or an LTC for a longer duration. This relationship would aim to help with understanding, sharing experiences/coping strategies, helping towards autonomy and self-determination. ${ }^{15}$ In addition, peer counselling also aids in providing sources of information, advice, support, referral and assistance. Peer counselling is important; it promotes support and mentoring between those who are egalitarian with each other. ${ }^{55}$

\section{Additional support from the Accessible Information Standard}

Making all forms of digital communication as easy to use by as many as possible is the remit of W3C's Web Accessibility Initiative. ${ }^{56}$ NHS England's “Accessible Information Standard" 57 has gone beyond. All providers of publicly-funded health and social care are obliged to support patients, carers and parents with "disability, impairments or sensory loss" directly, or indirectly, affecting communications. Channels of communication, such as email and text and methods for remote consultations, are covered. So too are provision of documents in alternative formats (such as large print or Easy Read) and face-to-face support at consultations (like sign language or advocates). The standard is backed by the Law, underpinning the widely accepted, moral and business cases. Though new, and still to become embedded in routine practice, the standard will inevitably add support to the growing evidence behind SM.

\section{Conclusion}

LTCs and disabilities are growing in prevalence and cost. Failure of healthcare systems to address these challenges is attributed, in significant ways, to the discrimination and ignorance of professionals and systems themselves, based on the stigma of consequential disability. Two examples, from CKD, have shown early evidence of genuine benefit for patients and families through SM/Facebook. The need was evidenced, development explained, co-development of digital and physical support outlined. The message from this paper is simple: SM has so much to offer in healthcare and beyond, needs nurturing, support and developmental research.

\section{References}

1. Muhammad S, Camilleri-Zahra A, Leicester H, Davis $\mathrm{H}$, Davis S. Can social media (SM) help raise discrimination and ignorance awareness for people with long term conditions (LTCs) providing a chronic kidney disease (CKD) example and assistive technology (AT) for people with disabilities? Patient Experience Network (PEN), Poster Presentation. February 2015. (Available from http://patientexperiencenetwork.org/resources/newsl 
etters/Feb_PenLetter2015.html). Accessed September 2015.

2. Department of Health. Long term conditions compendium of information. 3rd ed. London: Department of Health; 2012.

www.dh.gov.uk/prod_consum_dh/groups/dh_digitala ssets/@dh/@en/documents/digitalasset/dh_134486. pdf. Accessed January 5, 2016.

3. Barnett K, Mercer S, Norbury M, Watt G, Wyke S, Guthrie B. Epidemiology of multi-morbidity and implications for health care, research, and medical education: a cross-sectional study. Lancet. 2012; 380(9836): 37-43.

4. United Nations. United Nations Convention on the Rights of Persons with Disabilities. New York: United Nations; 2006.

5. World Health Organisation (WHO). Disability and Health Fact Sheet No 352. 2013.

(Available from: http://www.who.int/mediacentre/factsheets/fs352/en /2013). Accessed November 5, 2014.

6. World Health Organization (WHO). Global Disability Action Plan 2014-2021. 2014. (Available from: http://www.who.int/disabilities/actionplan/en/) Accessed November 4, 2014.

7. Beatty PW, Dhont KR. Medicare health maintenance organizations and traditional coverage: Perceptions of health care among beneficiaries with disabilities. Arch Phys Med Rehab. 2001; 82: 1009-1017.

8. Beatty PW, Hagglund KJ, Neri MT, Dhont KR, Clark $\mathrm{M} J$, Hilton SA. Access to health care services among people with chronic or disabling conditions: Patterns and predictors. Arch Phys Med Rehab. 2003; 84: 14171425.

9. Coughlin TA, Long SK, Kendall S. Health care access, use, and satisfaction among disabled Medicaid beneficiaries. Health Care Financ R. 2002; 24(2): 115136

10. Fouts BS, Andersen E, Hagglund K. Disability and satisfaction with access to health care. J Epidemiol Commun H. 2000; 54: 770-771.

11. Iezzoni L I, Davis R B, Soukup J, O’Day B. Satisfaction with quality and access to health care among people with disabling conditions. Int J for Qual Health C. 2000; 14(5): 369-381.

12. Kennedy J, Erb C. Prescription noncompliance due to cost among adults with disabilities in the United States. Am J Public Health. 2002; 92(7): 1120-1124.

13. Long SK, Coughlin TA, Kendall SJ. Access to care among disabled adults on Medicaid. Health Care Financ R. 2002; 23(4): 159-173.

14. Drainoni ML et al. Cross-disability experiences of barriers to health-care access. Journal of Disability Policy Studies. 2006; 17(2): 101-115.
15. Muhammad S, Milford DV, Carson A, Young H, Martin CR. Coping in Young People with CKD.J Renal Care. 2015. doi: 10.1111/jorc.12131

16. Sayce L. In the spotlight: The Equality Act. Ment Health Today. 2010; 9.

17. Thornicroft G, Rose D, Kassam A, Sartorius N. Stigma: ignorance, prejudice or discrimination? $\mathrm{Br} J$ Psychiatry. 2007; 190: 192-193.

18. Thornicroft G, Brohan E, Kassam A, Lewis-Holmes E. Reducing stigma and discrimination: Candidate interventions. Int J Ment Health Syst. 2008; 2(1): 3.

19. Clement S, Brohan E, Sayce L, Pool J, Thornicroft G. Disability hate crime and targeted violence and hostility: a mental health and discrimination perspective. J Ment Health. 2011; 20(3): 219-225.

20. Sayce, L. High time for justice. Nurs Times. 1999; 95(9): 64-66.

21. Sayce. L. In the spotlight: The Equality Act. Ment Health Today. 2010; 9.

22. Thornicroft G. Tackling discrimination. Ment Health Today. 2006; 26-29.

23. General Medical Council, 2012. (Available from: http://www.gmc-uk.org). Accessed November 5, 2014.

24. Mencap, 2012. Available from: www.mencap.org.uk. Accessed November 5, 2014.

25. Andersson F, Lyttkens CH. Preferences for equity in health behind a veil of ignorance. Health Econ. 1999; 8(5): 369-378.

26. Clement S, Brohan E, Sayce L, Pool J, Thornicroft G. Disability hate crime and targeted violence and hostility: a mental health and discrimination perspective. J Ment Health. 2011; 20(3): 219-225.

27. Kings Fund Workshop, 2001. (Available from: http://www.kingsfund.org.uk/). Accessed November 5, 2014.

28. Tech4goodawards, 2014. Available from: (Available from http://www.tech4goodawards.com/stephenhawking-receives-abilitynet-special-award/). Accessed November 5, 2014.

29. Nielsenwire. Social Networks/Blogs Now Account for One in Every Four and a Half Minutes Online.

(Available from http://blog.nielsen.com/nielsenwire/global/socialmedia-acc). Published 2013. Accessed March 6, 2016.

30. Xie B. Older adults' health information wants in the internet age: implications for patient-provider relationships. J Health Comm. 2009; 14: 510-524.

31. Timimi F. The Use of Social Media in Healthcare. (Available from http://newsblog.mayoclinic.org/2012/03/24/ farristimimi). Published 2012. Accessed on November 5, 2014. 
32. Mendelsohn S, Edyburn DL, Rust KL, Schwanke TD, Smith RO. Using assistive technology outcomes research to inform policy related to the employment of individuals with disabilities. Assist Technol. 2008; 20(3): 139-148.

33. Edyburn DL. Assistive technology and students with mild disabilities. Focus Except Child. 2000; 32(9): 1-24.

34. Edyburn DL. Measuring assistive technology outcomes in reading. J Spec Educ Tech. 2004; 19(1): 60-64.

35. Edyburn DL. Assistive technology and students with mild disabilities: From consideration to outcome measurement. In: Edyburn D, Higgins K, Boone R, eds. Handbook of special education technology research and practice. Whitefish Bay, WI: Knowledge by Design, Inc; 2005: 239-269.

36. Coulter A, Collins A. Shared decision making a reality, no decision about me without me.

(Available from

http://www.kingsfund.org.uk/sites/files/kf/Makingshared-decision-making-a-reality-paper-Angela-

Coulter-Alf-Collins-July-2011_0.pdf). Published 2011. Accessed on March 20, 2015.

37. Black C, Sharma P, Scotland G, et al. Early referral strategies for management of people with markers of renal disease: a systematic review of the evidence of clinical effectiveness, cost-effectiveness and economic analysis. Health Tech Assess. 2010; 14(21): 1-184.

38. De Jong PE, Hillege HL, Pinto-Sietsma SJ, de ZD. Screening for microalbuminuria in the general population: a tool to detect subjects at risk for progressive renal failure in an early phase? Nephrol Dial Transplant. 2003; 18(1): 10-13.

39. Kearns B, Gallagher H, de LS. Predicting the prevalence of chronic kidney disease in the English population: a cross-sectional study. BMC Nephrol. 2013; 14: 49 .

40. Lewington AJ, Cerda J, Mehta R. Raising awareness of acute kidney injury: a global perspective of a silent killer. Kidney Int. 2013; 84(3): 457-467.

41. Giles R. Viewpoint paper, Envisioning the digital hospital - The Future of Healthcare 2012. (Available from: http://www8.hp.com/uk/en/industries/publicsector.html?compURI=1464165\#.Vx4T-dIrKUk) Accessed September 2015

42. The Renal Patient Support Group (RPSG). (Available from: http://www.facebook.com/groups/RPSGroup/). Accessed January 31, 2016.

43. Muhammad S, Allan M, Ali F, Bonacina M, Adams M. The renal patient support group: supporting patients with chronic kidney disease through social media. J Ren Care. 2014; 40(3): 216-218.

44. Muhammad S, Noble H, Banks P, Carson A, Martin CR. How young people cope with chronic kidney disease: literature review. J Ren Care. 2012; 38(4): 182190

45. Morris N. Lord Freud: Tory welfare minister apologises after saying disabled people are 'not worth' the minimum wage. The Independent. October 15, 2014. (Available from http://www.independent.co.uk/news/uk/politics/lord -freud-tory-welfare-minister-accused-of-claimingdisabled-people-are-not-worth-the-minimum-wage9796062.html). Accessed December 16, 2015.

46. Shakespeare T, Watson N. Defending the Social Model. Disabil Soc. 1997; 12(2): 293 - 300.

47. Bain M, Licence K. The NHS must employ more people with disabilities. Health Service Journal (HSJ). 2015. Available from: (Available from http://www.hsj.co.uk/comment/the-nhs-mustemploy-more-people-withdisabilities / 5090449.article? referrer=RSS\#.VhAGwCC bPaK). Accessed September 15, 2015.

48. Mendelsohn S, Edyburn DL, Rust KL, Schwanke TD, Smith RO. Using assistive technology outcomes research to inform policy related to the employment of individuals with disabilities. Assist Technol. 2008; 20(3): 139-148.

49. Edyburn DL. Assistive technology and students with mild disabilities. Focus Except Child. 2000; 32(9): 1-24.

50. Edyburn DL. Measuring assistive technology outcomes in reading. J Spec Educ Tech. 2004; 19(1): 60-64.

51. Clement S, Brohan E, Sayce L, Pool J, Thornicroft G. Disability hate crime and targeted violence and hostility: a mental health and discrimination perspective. J Ment Health. 2011; 20(3): 219-225.

52. Thornicroft G, Rose D, Kassam A, Sartorius N. Stigma: ignorance, prejudice or discrimination? $\mathrm{BrJ}$ Psychiatry. 2007; 190: 192-193.

53. Galati M, Barbuto R, Coppede N, Meduri M, Napolitano E. Possible itineraries for women with disability. Empowerment and advocacy. Rome: Rubettino Editore; 2003.

54. Fuchs DM. Breaking down barriers: Independent living resource centres for empowering the physically disabled. In: Ismael JS, Thomlinson RJ, eds. Perspectives on Social Services and Social Issues. Ottawa: Canadian Council of Social Development; 1987.

55. W3C's Web Accessibility Initiative. 2015. (Available from: http://www.w3.org/WAI/)

Accessed September 5, 2015.

56. NHS England. Accessible Information Standard. (Available from: http2015://www.england.nhs.uk/accessibleinfo) Accessed September 5, 2015. 